\title{
Glycogen synthase kinase $3 \beta$ inhibition reduces mitochondrial oxidative stress in chronic myocardial ischemia
}

\author{
Brittany A. Potz, MD, Laura A. Scrimgeour, MD, Sharif A. Sabe, MD, Richard T. Clements, PhD, \\ Neel R. Sodha, MD, and Frank W. Sellke, MD
}

\section{ABSTRACT}

Objectives: Glycogen synthase kinase $3 \beta(\mathrm{GSK}-3 \beta)$ inhibition has been reported to increase microvascular density and improve myocardial blood flow in a porcine model of chronic myocardial ischemia and metabolic syndrome. Inhibition of GSK-3 $\beta$ can also be cardioprotective by modulating fibrosis signaling and mitochondrial-induced apoptosis. We hypothesized GSK-3 $\beta$ inhibition would have a beneficial effect on myocardial fibrosis and oxidative stress in a porcine model of chronic myocardial ischemia and metabolic syndrome.

Methods: Pigs were fed a high fat diet for 4 weeks followed by placement of an ameroid constrictor to the left circumflex coronary artery. Three weeks later animals received either no drug or a GSK-3 $\beta$ inhibitor. The diets and placebo/GSK-3 $\beta$ inhibition were continued for an additional 5 weeks, the pigs were then euthanized, and the myocardial tissue was harvested. Collagen expression was analyzed via Picrosirius staining. Oxidative stress was analyzed via Oxyblot analysis. Protein expression was analyzed via Western blot.

Results: GSK-3 $\beta$ inhibition was associated with decreased collagen expression and oxidative stress in the ischemic and nonischemic myocardial tissue compared with control. There was a decrease in profibrotic proteins transforming growth factor- $\beta$, p-SMAD2/3, and matrix metalloproteinase-9, and in proapoptotic and oxidative stress proteins, apoptosis inducing factor, the cleaved caspase 3/caspase 3 protein ratio and phosphorylated myeloid cell leukemia sequence- 1 in the GSK-3 $\beta$ inhibited group compared with the control.

Conclusions: In the setting of metabolic syndrome and chronic myocardial ischemia, inhibition of GSK- $3 \beta$ decreases collagen formation and oxidative stress in myocardial tissue. GSK-3 $\beta$ inhibition might be having this beneficial effect by downregulating transforming growth factor- $\beta /$ SMAD2/3 signaling and decreasing mitochondrial induced cellular stress. (J Thorac Cardiovasc Surg 2018;155:2492-503)

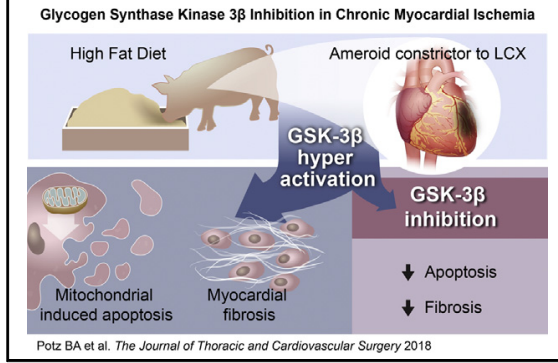

GSK-3 $\beta$ inhibition decreases fibrosis in ischemic myocardium in pigs with metabolic syndrome.

\section{Central Message}

GSK-3 $\beta$ inhibition might serve as a potential therapy to decrease myocardial fibrosis and oxidative stress in patients suffering from coronary artery disease and metabolic syndrome.

\section{Perspective}

In the setting of metabolic syndrome and chronic myocardial ischemia, inhibition of GSK-3 $\beta$ decreases collagen formation and oxidative stress in myocardial tissue. GSK- $3 \beta$ inhibition is associated with decreased profibrotic and mitochondrial-induced stress protein signaling. GSK-3 $\beta$ inhibition might serve as a therapy to inhibit myocardial fibrosis for patients suffering from coronary artery disease.

See Editorial Commentary page 2504.
From the Division of Cardiothoracic Surgery, Department of Surgery, Cardiovascular Research Center, Rhode Island Hospital, Alpert Medical School of Brown University, Providence, RI.

Funding for this research was provided by the National Heart, Lung, and Blood Institute (RO1HL128831, RO1 HL46716) (to F.W. Sellke); NIH T32 GM065085 training grant to (to L.A. Scrimgeour); and National Institutes of Health/National Institute of General Medical Sciences training grant 2T32 GM065085 to (to B.A. Potz); American Heart Association Grant-in-Aid GRNT20460376, and National Institute of General Medical Sciences U54GM115677 (to R.T. Clements).

Read at the 43rd Annual Meeting of The Western Thoracic Surgical Association, Colorado Springs, Colorado, June 21-24, 2017.

Received for publication May 11, 2017; revisions received Nov 21, 2017; accepted for publication Dec 29, 2017; available ahead of print March 6, 2018.

Address for reprints: Frank W. Sellke, MD, Division of Cardiothoracic Surgery, 2 Dudley St, MOC 360, Providence, RI 02905 (E-mail: fsellke@ lifespan.org).

$0022-5223 / \$ 36.00$

Copyright (c) 2018 by The American Association for Thoracic Surgery

https://doi.org/10.1016/j.jtcvs.2017.12.127
Metabolic syndrome is a diagnosis encompassing a host of pathologic conditions observed in cardiovascular disease states including hypertension, obesity, hyperlipidemia, and glucose intolerance/diabetes mellitus type 2 . The incidence of metabolic syndrome is approximately $24 \%$ in the United States. ${ }^{1}$ Patients with metabolic syndrome are at increased

Scanning this $\mathrm{QR}$ code will take you to a supplemental video for the article.

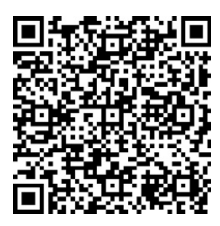




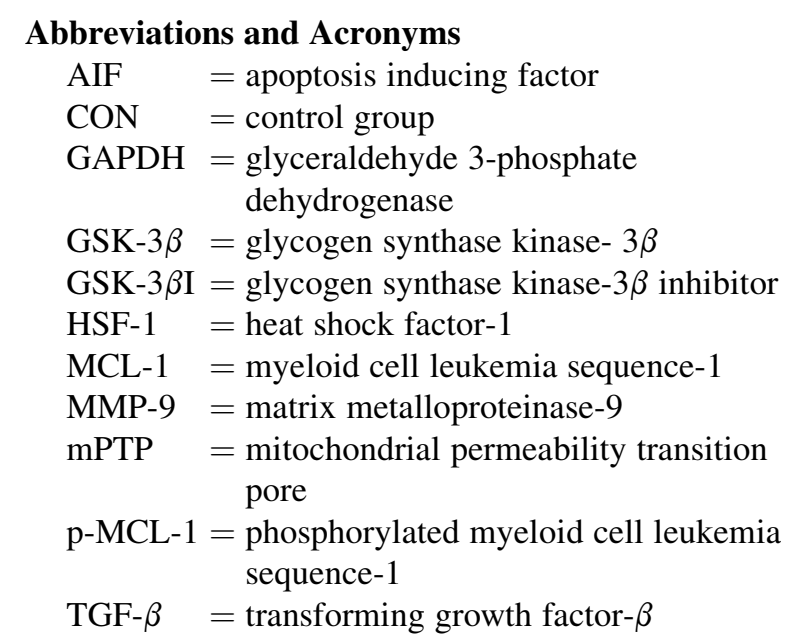

risk for cardiovascular disease. ${ }^{2,3}$ Furthermore, coronary artery disease, vascular disease, and total mortality are increased in adults with metabolic syndrome., ${ }^{2,3}$ The mechanism by which metabolic syndrome leads to the previously mentioned cardiovascular conditions is multifactorial. ${ }^{4}$

Glycogen synthase kinase $3 \beta$ (GSK-3 $\beta$ ) is a serine/ threonine kinase that regulates a diverse range of cellular pathways. GSK- $3 \beta$ hyperactivation is associated with several pathologic conditions including type 2 diabetes, obesity, retinal ischemia, coronary artery disease, myocardial fibrosis, and elevated levels of inflammation and oxidative stress. $^{5-8}$ Although hyperactivation of GSK-3 $\beta$ is detrimental, some level of physiologic GSK- $3 \beta$ activity is necessary for life because global GSK- $3 \beta$ knockout is lethal. ${ }^{7,9,10}$ Inhibition of GSK-3 $\beta$ overactivity has been reported to beneficially reverse some of these pathologic conditions by modulating insulin signaling, improving glucose disposal in diabetes by improving liver glycogen synthesis, decreasing transforming growth factor- $\beta$ (TGF- $\beta$ )/SMAD3-induced fibrosis after renal ischemia/ reperfusion, and improving neovascular formation in the setting of retinal ischemia. ${ }^{7,10-13}$

Hyperglycemia and ischemic coronary disease contribute to myocardial remodeling via apoptosis and the accumulation of myocardial collagen leading to aberrant myocardial architecture ultimately resulting in cardiac dysfunction and heart failure. ${ }^{14,15}$ Inhibition of stressinduced myocardial fibrosis is therefore cardioprotective. ${ }^{15-18}$ GSK-3 $\beta$ activity has been implicated in the fibrosis that develops in ischemia/reperfusion injury. ${ }^{13}$ Similarly, GSK- $3 \beta$ knockout mice have reduced left ventricular remodeling and preserved left ventricular dysfunction in the setting of permanent myocardial infarction. ${ }^{19}$ GSK- $3 \beta$ is thought to regulate fibrosis by $\beta$ catenin-dependent and TGF- $\beta$-SMAD 3 -dependent mechanisms. ${ }^{20}$

Mitochondrial oxidative stress leads to opening of the mitochondrial permeability transition pore (mPTP), which plays a critical role in myocardial apoptosis. ${ }^{21,22}$ Suppression of mPTP opening is cardioprotective against reperfusion injury in rats. ${ }^{21}$ GSK- $3 \beta$ phosphorylates and inhibits myeloid cell leukemia sequence-1 (MCL-1), which regulates formation of mPTP. ${ }^{6,8,23}$ GSK- $3 \beta$ inhibition is also thought to be cardioprotective by modulating fibrosis signaling and cardiomyocyte hypertrophy, limiting infarct size in animals models of acute myocardial infarction, reducing oxidative stress, and preventing $\mathrm{mPTP}$ opening in myocardial reperfusion injury. ${ }^{13,24-27}$

In this study we used a porcine model of chronic coronary artery disease and myocardial ischemia in the setting of metabolic syndrome. This model represents the circulatory and metabolic dysfunction observed in adult patients with metabolic syndrome and chronic coronary artery disease. ${ }^{28}$ Using this model, we have found that inhibition of GSK-3 $\beta$ increases blood flow and vessel density in ischemic and nonischemic myocardial tissue. ${ }^{29}$

The objective of this study was to examine the effects of inhibition of GSK-3 $\beta$ on myocardial fibrosis and oxidative stress in the setting of chronic myocardial ischemia and metabolic syndrome. We hypothesized that GSK-3 $\beta$ inhibition would have a protective effect on myocardial collagen formation and oxidative stress.

\section{METHODS}

\section{Animal Model}

Sixteen Yorkshire swine (E.M. Parsons and Sons, Hadley, Mass) were fed a $500 \mathrm{~g} / \mathrm{d}$ high fat/high cholesterol diet for 4 weeks (Sinclair Research, Columbia, Mo). ${ }^{28}$ This diet consists of $4 \%$ cholesterol, $2.3 \%$ corn oil $17.2 \%$ coconut oil, $1.5 \%$ sodium cholate, and $75 \%$ regular chow.

The swine received aspirin $(10 \mathrm{mg} / \mathrm{kg}) 1$ day preoperatively and 5 days postoperatively and cephalexin $(30 \mathrm{mg} / \mathrm{kg}) 1$ day preoperatively and 5 days postoperatively. Anesthesia was then induced with telazol $(4.4 \mathrm{mg} / \mathrm{kg})$ and xylazine $(2.2 \mathrm{mg} / \mathrm{kg})$ and maintained with isoflurane $(0.75 \%-3 \%)$. A 72-hour fentanyl patch ( $4 \mu \mathrm{g} / \mathrm{kg}$ ) was placed before surgery. A left mini thoracotomy was then performed, the left circumflex artery was identified and manually occluded for 2 minutes while gold microspheres $(5 \mathrm{cc}$, BioPal, Worcester, Mass) were injected into the left atrium to allow for microsphere labeling of the nonischemic territory. Heparin (80 IU/kg) was injected before occlusion. To induce chronic myocardial ischemia, a titanium ameroid constrictor ring (Research Instruments SW, Escondido, Calif) was placed on the left circumflex coronary artery. The hydrophilic core of the ameroid constrictor enlarges gradually over the course of 10 to 20 days to reproduce a chronic model of ischemia. Amiodarone $(10 \mathrm{mg} / \mathrm{kg}$ ) was used as needed for arrhythmias that developed as a result of isolation and manipulation of the left circumflex artery at the time of ameroid placements

Two weeks later, the animals were split into 2 groups and received either a placebo (high cholesterol control group, $1.5 \mathrm{mg} / \mathrm{kg} / \mathrm{d}$ of DMSO, termed as "CON" group; $\mathrm{n}=8)$; or a GSK-3 $\beta$ inhibitor $(G S K-3 \beta I$; $1.5 \mathrm{mg} / \mathrm{kg} / \mathrm{d}$ dissolved in DMSO, termed as "GSK-3 $\beta \mathrm{I}$ ” group; $\mathrm{n}=8$ ) 
The high cholesterol diet and GSK-3 $\beta$ I was continued for 5 weeks (once a day for 6 of 7 days a week).

Five weeks after the start of treatment, pigs were placed under general anesthesia and the terminal procedure was performed. The heart was exposed through a sternotomy, coronary angiography was performed, and microspheres were injected at rest (Lutetium, $5 \mathrm{cc}$; BioPal) and with pacing ( 150 beats per minute; Samarium, $5 \mathrm{cc}$; BioPal) in the left atrium while simultaneously withdrawing blood from a femoral artery catheter. Euthanasia was performed using exsanguination under deep anesthesia. Myocardial and peripheral organ tissue was collected. Tissue was collected from the chronically ischemic myocardium (circumflex artery territory) and the nonischemic (anterior descending artery territory) myocardium. Ischemic tissue was identified on the basis of the proximity to the left circumflex (distal to the ameroid constrictor) and nonischemic tissue was identified on the basis of the proximity to the left anterior descending artery. This tissue was either rapidly frozen in liquid nitrogen or placed in formalin. One pig died at the end of the ameroid placement procedure as a result of difficulty with anesthesia. The pig became bradycardic and hypocarbic before going into cardiac arrest during closing of the incision. This pig was excluded from the study. The Rhode Island Hospital Institutional Animal Care and Use Committee approved and supervised all experiments. The Principles of Laboratory Animal Care formulated by the National Society for Medical Research and the Guide for the Care and Use of Laboratory Animals were used to ensure proper care of all animals.

A glucose tolerance test was performed before the start of the ameroid and harvest procedures. We administered $0.5 \mathrm{~g} / \mathrm{kg}$ of $50 \%$ dextrose at the start of the surgery and glucose was measured at 30 and 60 minutes. The pigs were measured for length and weight before the start of the ameroid and harvest procedures. Blood taken at the time of the harvest procedure was sent to the Rhode Island Hospital chemistry lab for quantification of cholesterol parameters. There were no differences in glucose levels, weight, or cholesterol parameters between the control and GSK-3 $\beta$ inhibited groups. ${ }^{29}$

\section{Picrosirius Red Staining}

Picrosirius red staining was performed on approximately $1 \mathrm{~cm}^{2}$ tissue sections using the Picrosirius Red Stain Kit (Polysciences, Inc,
Warrington, Pa). Tissue slides containing paraffin sections were dewaxed and hydrated, nuclei were stained with Weigert's hematoxylin and the sections were then washed with running tap water. Picrosirius stain was applied to the tissue slides for 1 hour after which the slides were washed in 2 changes of acidified water. Water was removed and dehydration was performed using 3 changes of $100 \%$ ethanol. The tissue was cleared in xylene and mounted in a resinous medium. Images were captured at $20 \times$ magnification with a Nikon E800 Eclipse microscope (Nikon, Tokyo, Japan) at the same exposure in 5 random fields. Image $\mathbf{J}$ software (National Institutes of Health, Bethesda, Md) was used to measure collagen expression in a blinded fashion. Representative images are included (Figures 1 and 2).

\section{Oxidative Stress}

Oxyblot (Millipore, Billerica, Mass) was performed on the ischemic and nonischemic myocardial tissue as described by the manufacturer. Tissue was lysed in Radioimmunoprecipitation Assay buffer (Boston BioProducts, Ashland, Mass) and 2 aliquots of each specimen were analyzed (1 aliquot was subjected to a derivatization reaction, the other aliquot served as a negative control). For each pig, $5 \mu \mathrm{L}$ of protein sample was divided into 2 Eppendorf tubes and then denatured with $12 \%$ sodium dodecyl sulfate. For the positive control, 2,4 dinitrophenylhydrazine solution was used to derivatize the samples. Derivatization control solution was used in the control samples. Both sets of samples were incubated at room temperature for 15 minutes. Neutralization solution was then added. Both samples were then loaded onto a polyacrylamide gel and imaged as described in Figure 3.

\section{Protein Expression}

Western blot analysis was conducted as previously described. ${ }^{30}$ Tissue was lysed in radioimmunoprecipitation assay buffer (Boston BioProducts); $40 \mu \mathrm{g}$ was fractionated using sodium dodecyl sulfide polyacrylamide gel electrophoresis using 3\% to $8 \%$ Tris-Acetate gels (NuPage Novex Mini Gel; Thermo Fisher, Waltham, Mass), and the protein was transferred to polyvinylidene difluoride membranes (Millipore) and incubated overnight at $4^{\circ} \mathrm{C}$ with primary antibodies against cleaved caspase 3, caspase 3 , phosphorylated (serine 140) MCL-1, TGF- $\beta$, phosphorylated-SMAD2/3,

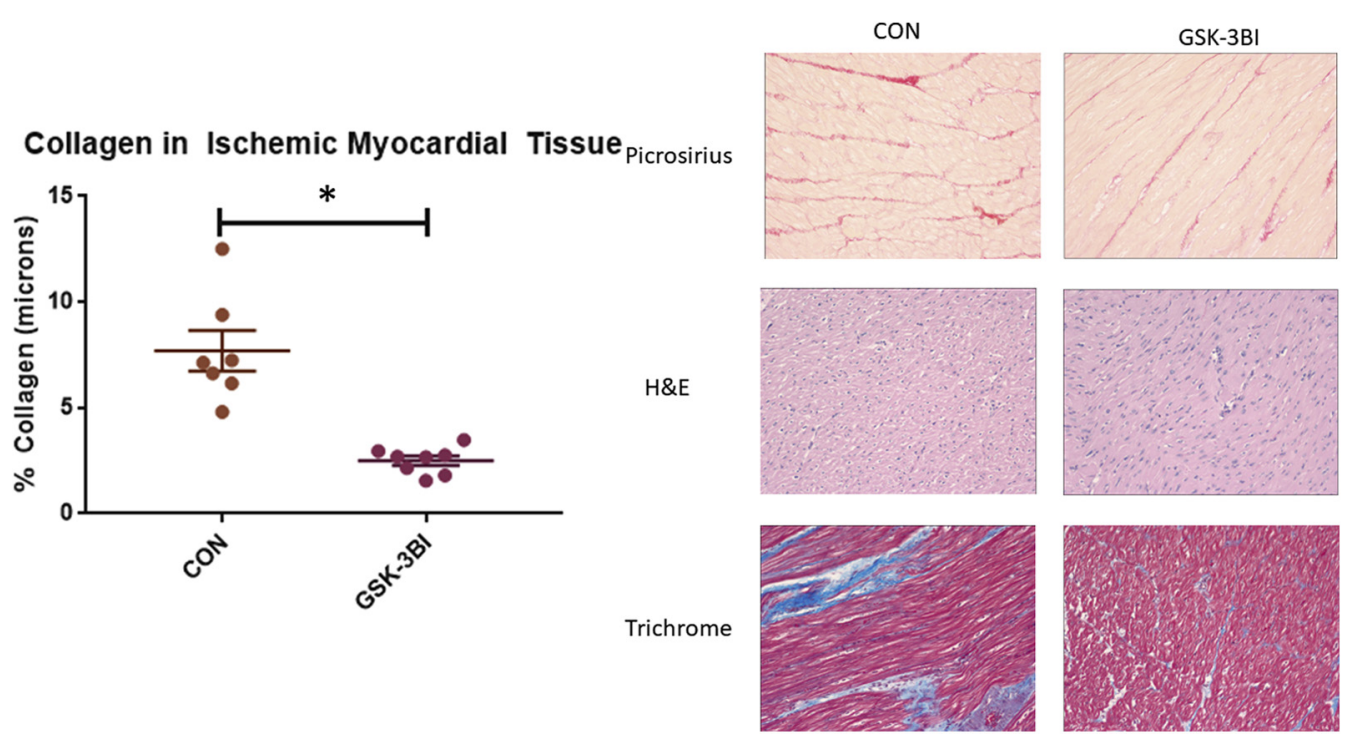

FIGURE 1. Glycogen synthase kinase $3 \beta$ (GSK-3 $\beta$ ) inhibition decreases fibrosis and collagen expression in ischemic myocardium in metabolic syndrome pigs. GSK-3 $\beta$ inhibition decreased collagen formation in the ischemic myocardium compared with the high cholesterol control group $(C O N ; \mathrm{n}=7)$. Representative images for Picrosirius, hematoxylin and eosin $(H \& E)$, and Trichrome staining for each pig group staining shown to right of graph. GSK-3 $\beta I$, GSK-3 $\beta$ inhibited group $(\mathrm{n}=8)$. $* P<.05$, Mann-Whitney $U$ test. 
CON

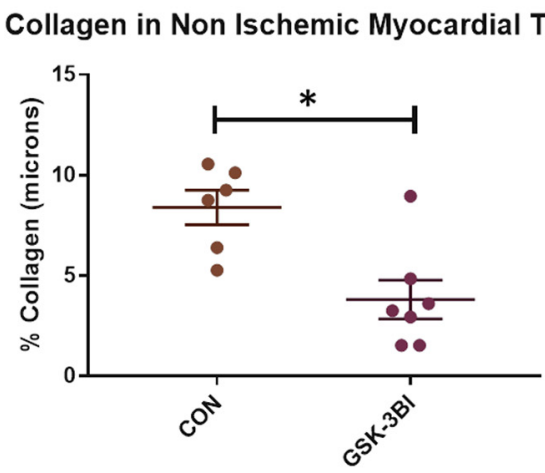

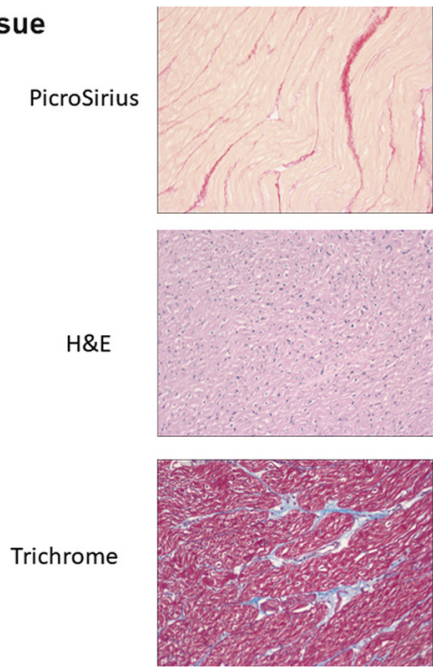

GSK-3BI
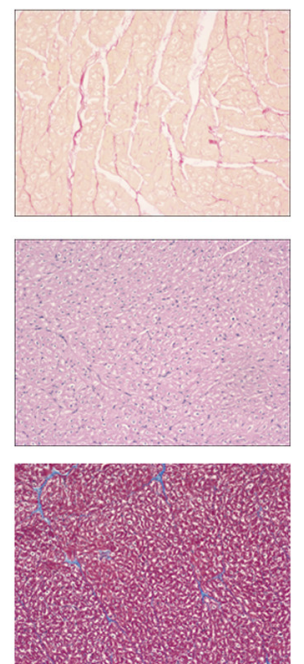

FIGURE 2. Glycogen synthase kinase $3 \beta(\mathrm{GSK}-3 \beta)$ inhibition decreases fibrosis and collagen expression in nonischemic myocardium in metabolic syndrome pigs. GSK-3 $\beta$ inhibition decreased collagen formation in the ischemic myocardium compared with the high cholesterol control group $(C O N ; \mathrm{n}=6)$. Representative images for Picrosirius, hematoxylin and eosin $(H \& E)$, and Trichrome staining for each pig group; staining shown to right of graph. $G S K-3 \beta I$, GSK-3 $\beta$ inhibited group $(\mathrm{n}=7)$. $* P<.05$, Mann-Whitney $U$ test.

matrix metalloproteinase-9 (MMP-9), apoptosis inducing factor (AIF), and heat shock factor-1 (all from Cell Signaling, Danvers, Mass). Twenty-four hours later, the membranes were incubated with the appropriate horseradish peroxidase-linked secondary antibody for 1 hour at room temperature (Jackson ImmunoResearch, West Grove, Pa). Immune complexes were visualized with enhanced chemiluminescence. Images were captured with a digital camera system (G-Box; Syngene, Cambridge, England). Image $\mathbf{J}$ software (National Institutes of Health) was used to quantify band densitometry as arbitrary light units. Loading error was controlled for by probing membranes with an antibody against glyceraldehyde 3-phosphate dehydrogenase.

\section{Data Analysis}

Results are reported as a mean \pm standard error of the mean. GraphPad 5.0 Software (GraphPad Software Inc, San Diego, Calif) was used to perform unpaired Mann-Whitney $U$ test between the GSK-3 $\beta$ I and CON groups. Protein expression was normalized to glyceraldehyde 3-phosphate dehydrogenase in all pigs and is reported as fold change compared with the $\mathrm{CON}$ group.

\section{RESULTS}

\section{GSK-3 $\beta$ Inhibition Decreases Fibrosis and Collagen Expression in Pigs With Metabolic Syndrome}

Inhibition of GSK-3 $\beta$ decreased myocardial fibrosis assessed using Picrosirius red staining compared with the control group. GSK-3 $\beta$ inhibition reduced fibrosis in the ischemic (Figure 1) as well as nonischemic myocardial tissue compared with the control (Figure 2).
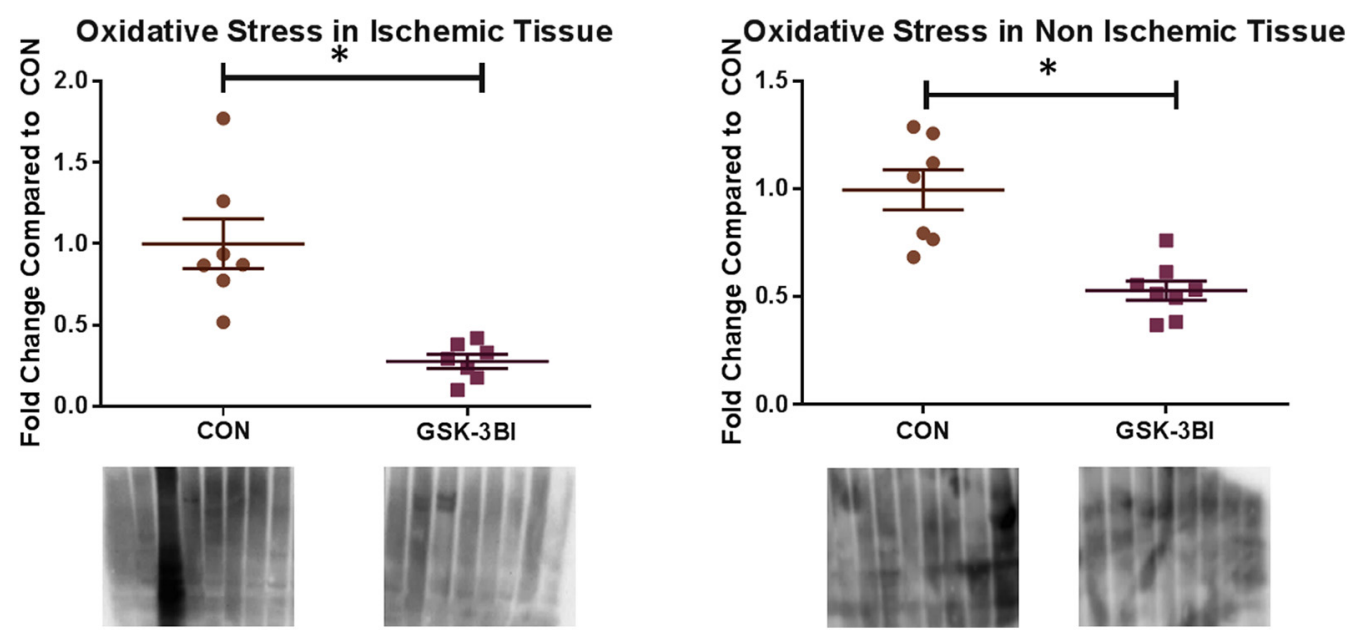

FIGURE 3. Glycogen synthase kinase $3 \beta$ (GSK- $3 \beta$ ) inhibition decreases oxidative stress in ischemic and nonischemic myocardium in metabolic syndrome pigs. GSK-3 $\beta$ inhibition decreased oxidative stress in the ischemic and nonischemic myocardium compared with the high cholesterol control group

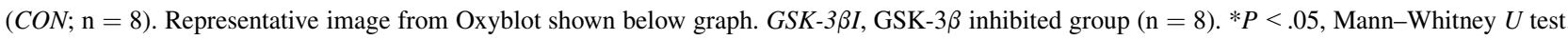



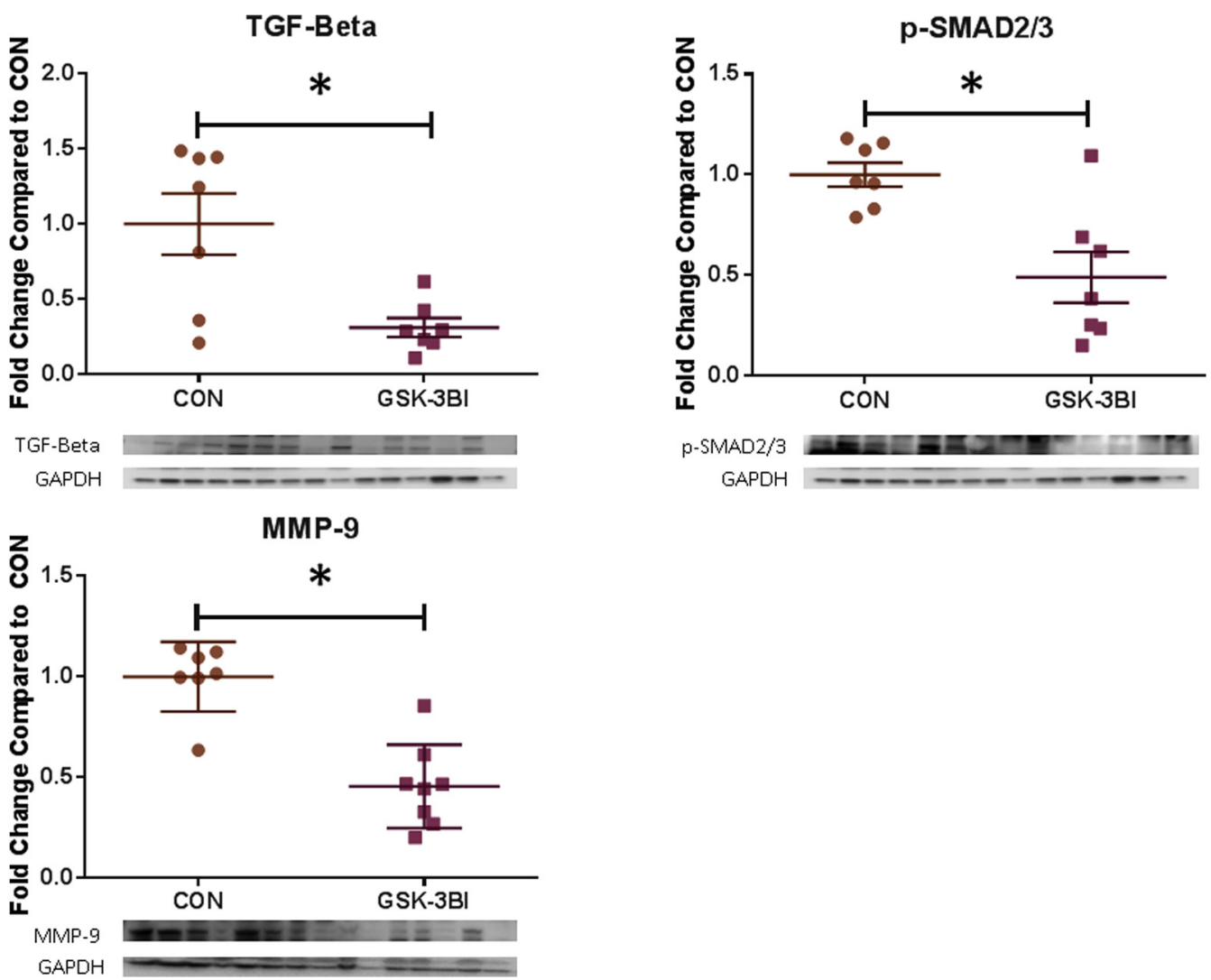

FIGURE 4. Glycogen synthase kinase $3 \beta$ (GSK-3 $\beta$ ) inhibition decreases profibrotic signaling in ischemic myocardial tissue in metabolic syndrome pigs. GSK-3 $\beta$ inhibition decreased transforming growth factor- $\beta(T G F-\beta)$, p-SMAD2/3, and MMP-9 in the ischemic myocardium compared with the high cholesterol control group $(C O N ; \mathrm{n}=7)$. Representative images from Western blot shown below graph. GAPDH, Glyceraldehyde 3-phosphate dehydrogenase; $M M P-9$, matrix metalloproteinase-9; $G S K-3 \beta I$, GSK-3 $\beta$ inhibited group $(\mathrm{n}=7) . * P<.05$, Mann-Whitney $U$ test.

GSK-3 $\beta$ Inhibition Decreases Oxidative Stress in Metabolic Syndrome Pigs

Inhibition of GSK-3 $\beta$ decreased oxidative stress in the GSK-3 $\beta$ inhibited pigs assessed using measurement of protein carbonyls with Oxyblot. GSK-3 $\beta$ inhibition reduced tissue oxidative stress in the ischemic as well as nonischemic myocardial tissue in the GSK- $3 \beta$ inhibited group compared with the control group (Figure 3).

TABLE 1. GSK-3 $\beta$ inhibition downregulates TGF- $\beta /$ SMAD2/3 signaling and mitochondrial-induced cellular stress

\begin{tabular}{|c|c|c|c|c|c|c|c|}
\hline \multicolumn{4}{|c|}{ Ischemic myocardial tissue } & \multicolumn{4}{|c|}{ Nonischemic myocardial tissue } \\
\hline Protein & CON & GSK-3 $\beta$ I & $P$ value & Protein & CON & GSK-3 $\beta$ I & $P$ value \\
\hline TGF- $\beta$ & $1.0 \pm 0.20$ & $0.43 \pm 0.13$ & $<.03$ & TGF- $\beta$ & $1.0 \pm 0.13$ & $0.29 \pm 0.07$ & .0006 \\
\hline p-SMAD2/3 & $1.0 \pm 0.06$ & $0.69 \pm 0.23$ & .007 & p-SMAD2/3 & $1.0 \pm 0.14$ & $0.43 \pm 0.10$ & .006 \\
\hline MMP-9 & $1.0 \pm 0.07$ & $0.45 \pm 0.07$ & .006 & MMP-9 & $1.0 \pm 0.27$ & $0.44 \pm 0.11$ & .054 \\
\hline AIF & $1.0 \pm 0.12$ & $0.70 \pm 0.21$ & $<.01$ & AIF & $1.0 \pm 0.27$ & $1.07 \pm 0.29$ & .96 \\
\hline Cleaved/total caspase 3 & $1.0 \pm 0.13$ & $0.62 \pm 0.07$ & .01 & Cleaved caspase 3 & $1.0 \pm 0.25$ & $0.58 \pm 0.20$ & $<.007$ \\
\hline p-MCL-1 & $1.0 \pm 0.19$ & $0.33 \pm 0.03$ & .0003 & p-MCL-1 & $1.0 \pm 0.15$ & $0.31 \pm 0.05$ & $<.006$ \\
\hline HSF-1 & $0.88 \pm 0.16$ & $0.75 \pm 0.09$ & .09 & & & & \\
\hline
\end{tabular}

Results are reported as a mean \pm standard error of the mean. GraphPad 5.0 Software (GraphPad Software Inc, San Diego, Calif) was used to perform unpaired Mann-Whitney $U$ test between the GSK-3 $\beta I(n=7)$ and CON $(n=7)$ groups. Protein expression is normalized to GAPDH in all pigs and is reported as fold change compared with CON group. ${ }^{*} P<.05$, Mann-Whitney $U$ test. $C O N$, High-cholesterol control group; GSK-3 $\beta I$, glycogen synthase kinase-3 $\beta$ inhibitor; TGF- $\beta$, transforming growth factor- $\beta$; $M M P-9$, matrix metalloproteinase-9; AIF, apoptosis inducing factor; $p-M C L-1$, phosphorylated myeloid cell leukemia sequence-1; HSF-1, heat shock factor-1. 

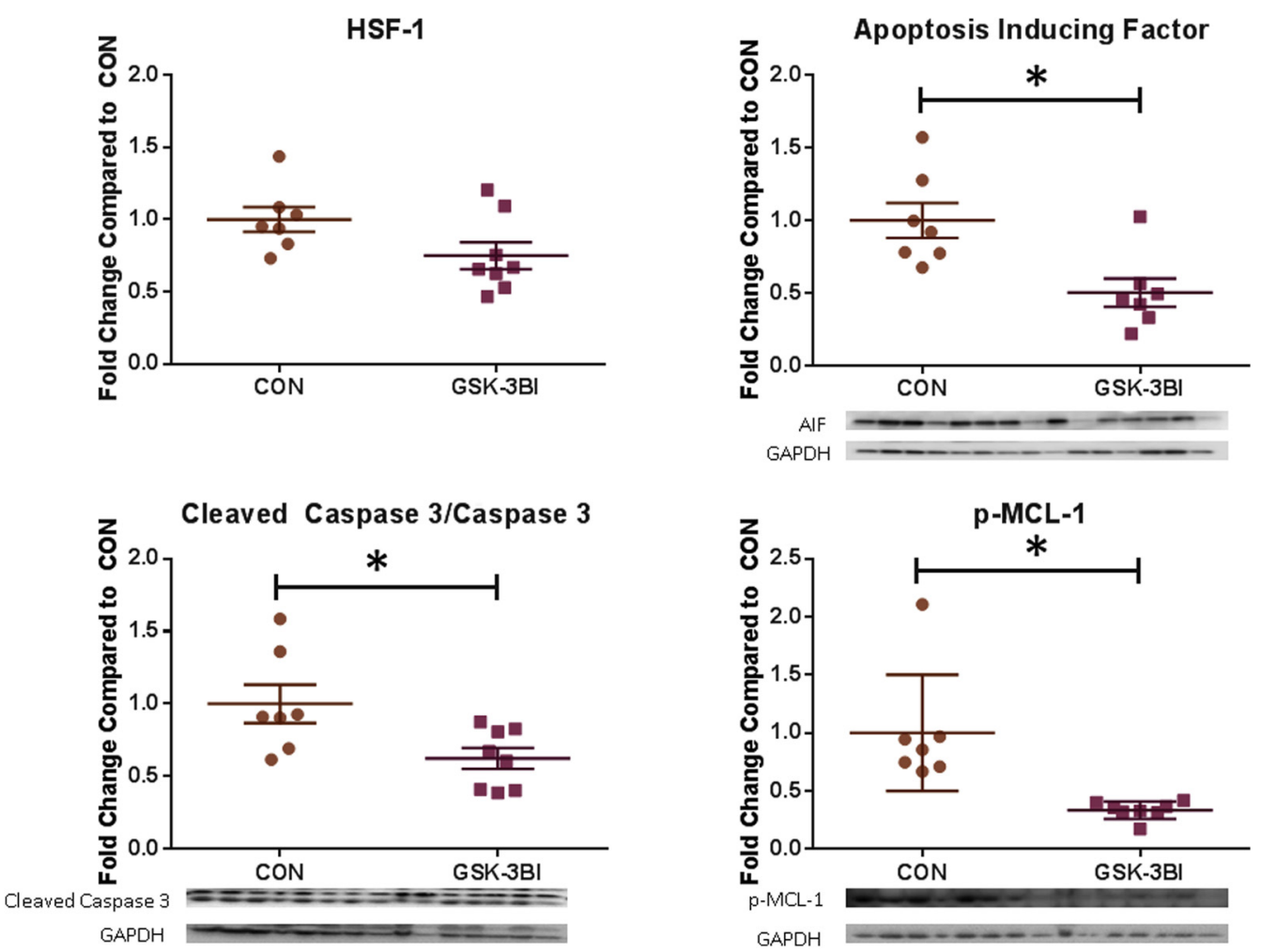

FIGURE 5. Glycogen synthase kinase $3 \beta$ (GSK-3 $\beta$ ) inhibition decreases mitochondrial proapoptotic signaling in ischemic in myocardial tissue in metabolic syndrome pigs. GSK-3 $\beta$ inhibition decreased apoptosis inducing factor, phosphorylated myeloid cell leukemia sequence-1 (Ser 140; $p$-MCL-1), and the ratio of cleaved caspase 3/caspase 3 in the ischemic myocardium compared with the high cholesterol control group $(C O N ; \mathrm{n}=8)$. Representative images from Western blot shown below graph. HSF-1, Heat shock factor-1; GSK-3 $\beta I$, GSK-3 $\beta$ inhibited group (n = 8); AIF, apoptosis inducing factor; $p$ - $M C L-1$, phosphorylated myeloid cell leukemia sequence-1. ${ }^{*} P<.05$, Mann-Whitney $U$ test.

\section{GSK-3 $\beta$ Inhibition Decreases Profibrotic Signaling in Ischemic Myocardial Tissue in Metabolic Syndrome Pigs}

Inhibition of GSK-3 $\beta$ decreased expression of the profibrotic cytokine TGF- $\beta$ and phosphorylation of its downstream effector protein $\mathrm{p}-\mathrm{SMAD} 2 / 3$. Inhibition of GSK-3 $\beta$ also decreased expression of extracellular matrix remodeling protein MMP-9 in the ischemic myocardial tissue compared with the control (Figure 4 and Table 1).

\section{GSK-3 $\beta$ Inhibition Reduces Apoptotic Signaling Pathways in Ischemic Myocardial Tissue in Pigs With Metabolic Syndrome}

Inhibition of GSK-3 $\beta$ reduced levels of the proapoptotic protein AIF compared with control pigs. Inhibition of GSK$3 \beta$ also decreased the ratio of cleaved/total caspase 3 compared with the control. Inhibition of GSK-3 $\beta$ was also associated with decreased expression of the phosphorylated, inactive, form of antiapoptotic MCL-1 in the ischemic myocardial tissue compared with the control. There was no significant difference in the expression levels of heat shock factor-1 $(P=.093$; Figure 5 and Table 1$)$.
GSK-3 $\beta$ Inhibition Decreases Profibrotic Signaling in Nonischemic Myocardial Tissue in Metabolic Syndrome Pigs

Inhibition of GSK-3 $\beta$ resulted in decreased expression of the profibrotic cytokine TGF- $\beta$ and phosphorylation of its downstream effector protein SMAD2/3 compared with the control pigs (Figure 6 and Table 1). There was no significant difference in the expression level of extracellular matrix remodeling protein MMP-9 between the 2 groups $(P=.054)$.

\section{GSK-3 $\beta$ Inhibition Reduces Apoptotic Signaling Pathways in Nonischemic Myocardial Tissue in Metabolic Syndrome Pigs}

Inhibition of GSK- $3 \beta$ was associated with a decreased expression of proapoptotic protein cleaved caspase 3 compared with the control. Inhibition of GSK- $3 \beta$ was also associated with decreased expression of the phosphorylated, inactive, form of antiapoptotic MCL-1 in the ischemic myocardial tissue compared with the control. There was no significant difference in $\operatorname{AIF}(P=.96$; Figure 7 and Table 1). 

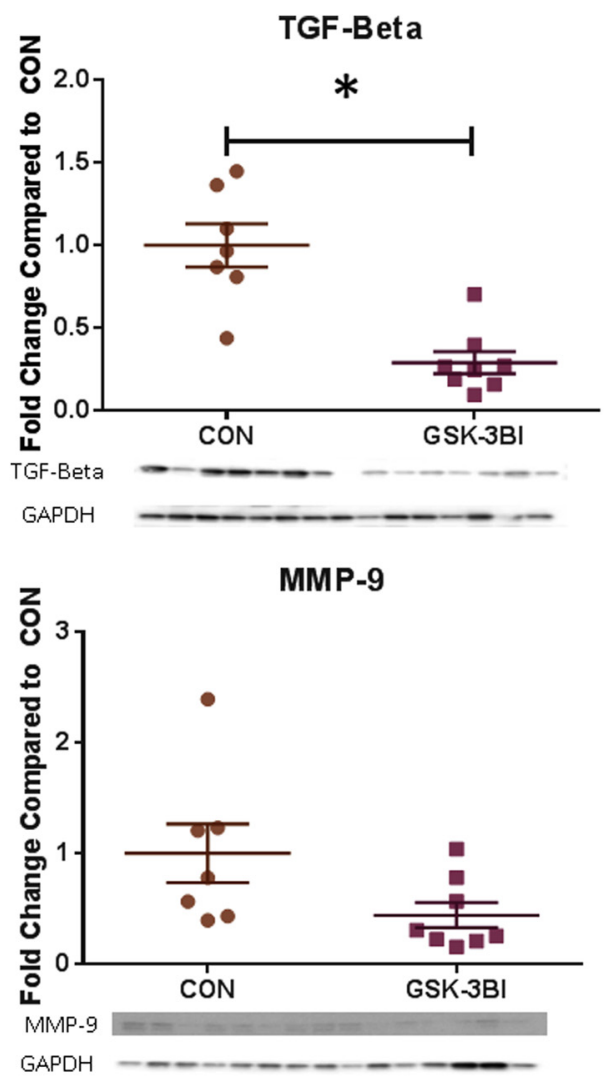

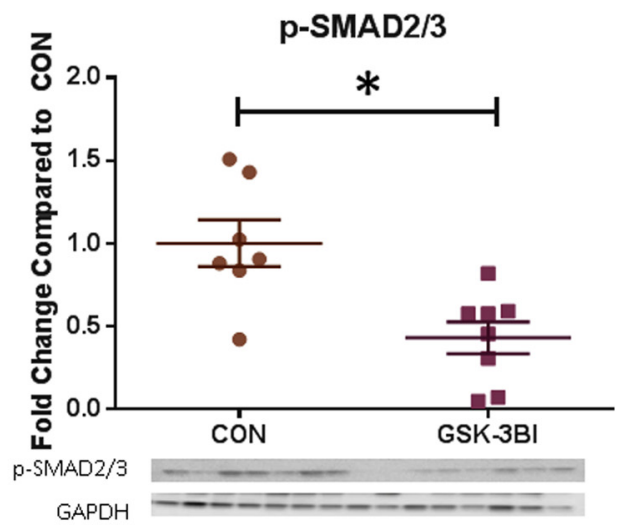

FIGURE 6. Glycogen synthase kinase $3 \beta(\mathrm{GSK}-3 \beta)$ inhibition decreases profibrotic signaling in nonischemic myocardial tissue in metabolic syndrome pigs. GSK-3 $\beta$ inhibition decreased transforming growth factor- $\beta$ (TGF- $\beta$ ) and p-SMAD $2 / 3$ in the nonischemic myocardium compared with the high cholesterol control group $(C O N ; \mathrm{n}=7)$. Representative images from Western blot shown below graph. GAPDH, Glyceraldehyde 3-phosphate dehydrogenase;

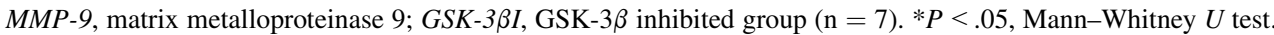

\section{DISCUSSION}

In this study, we examined the role of GSK- $3 \beta$ on the development of myocardial fibrosis and oxidative stress in the setting of chronic myocardial ischemia and metabolic syndrome. We found that inhibition of GSK- $3 \beta$ decreases collagen formation and oxidative stress in ischemic as well as nonischemic myocardial tissue. GSK-3 $\beta$ inhibition might mediate this beneficial effect via downregulation of TGF- $\beta /$ SMAD $2 / 3$ signaling and decreasing mitochondriainduced oxidative stress and apoptosis (Figure 8).

Accumulation of extracellular matrix proteins including collagen leads to aberrant myocardial architecture ultimately resulting in cardiac dysfunction and heart failure. ${ }^{14}$ Hyperglycemia and ischemic disease are both known to contribute to the development of cardiac fibrosis. ${ }^{14,15} \mathrm{In}$ our study, inhibition of GSK-3 $\beta$ decreased fibrosis and collagen deposition in the ischemic and nonischemic myocardial tissue. This is consistent with previous research showing that downregulation of GSK-3 $\beta$ is cardioprotective, associated with decreased infarct size myocardial fibrosis, and hypertrophy in small animal models of myocardial infarction and cardiac hypertrophy. ${ }^{31,32}$ In our study, GSK-3 $\beta$ inhibition decreased expression of the profibrotic cytokine TGF- $\beta$ and phosphorylation of its downstream transcription factor SMAD2/3 in the ischemic myocardial tissue. This suggests a mechanism through which GSK- $3 \beta$ might be inducing enhanced fibrosis in the setting of chronic myocardial ischemia and metabolic syndrome.

Interestingly, inhibition of GSK-3 $\beta$ with lithium in rats can lead to increased cardiac hypertrophy. ${ }^{25,33}$ However, the role of GSK-3 $\beta$ in fibrosis is controversial. In a mouse model of renal fibrosis induced by ischemia/reperfusion injury, GSK-3 $\beta$ inhibition was shown to suppress renal fibrosis by reducing TGF- $\beta 1 / \mathrm{SMAD}-3$ signaling. ${ }^{13}$ In a mouse model of myocardial infarction, GSK- $3 \beta$ was thought to inhibit fibrosis and left ventricular remodeling by inhibiting TGF- $\beta 1 / \mathrm{SMAD}-3$ signaling via interaction with SMAD-3. However, the exact mechanism of this interaction was undetermined. ${ }^{25}$ Nevertheless, in our large animal model of diet-induced metabolic syndrome, we observe a reduction in fibrosis and profibrotic signals in the ischemic as well as nonischemic myocardium.

Cardiac fibrosis is associated with dysregulation of the extracellular matrix. Matrix metalloproteinase 2 and 9 are known to process a number of collagens. ${ }^{17}$ Interestingly, 

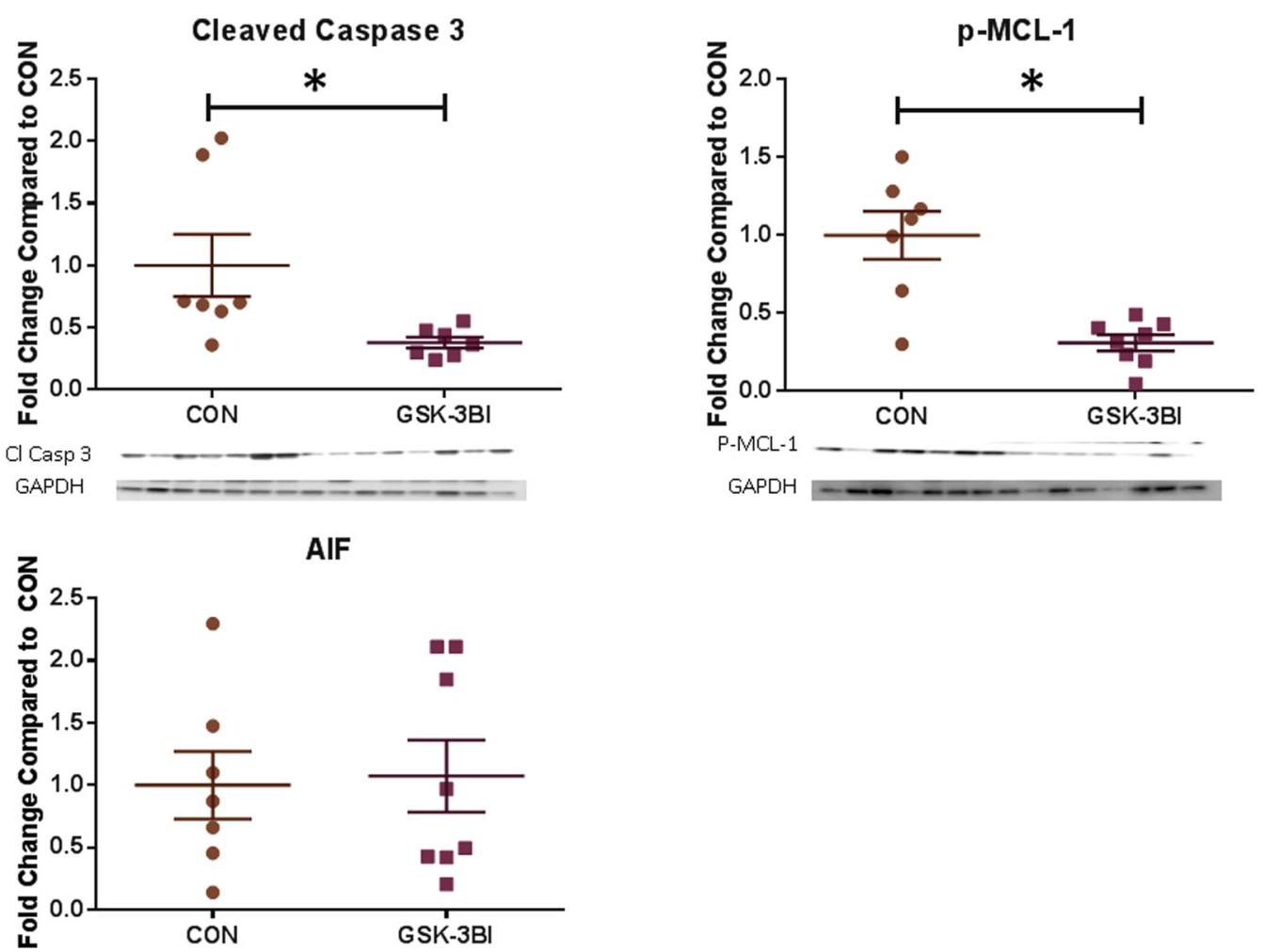

FIGURE 7. Glycogen synthase kinase $3 \beta$ (GSK-3 $\beta$ ) inhibition decreases mitochondrial proapoptotic signaling in the nonischemic myocardial tissue in metabolic syndrome pigs. GSK-3 $\beta$ inhibition decreased phosphorylated myeloid cell leukemia sequence-1 (Ser 140; $p$-MCL-1) and cleaved caspase 3 in the ischemic myocardium compared to the high cholesterol control group $(C O N ; \mathrm{n}=7)$. Representative images from Western blot shown below graph. $G A P D H$, Glyceraldehyde 3-phosphate dehydrogenase; GSK-3 $\beta I$, GSK-3 $\beta$ inhibited group $(\mathrm{n}=7) . * P<.05$, Mann-Whitney $U$ test.

reduced matrix metalloproteinase 2 activity has been shown to contribute to ischemic heart disease in diabetic mice. ${ }^{34}$ Tissue inhibitor of metalloproteinase-2 is associated with cardiac fibrosis and dysfunction in chronically pressureoverloaded human hearts. ${ }^{35}$ Additionally, acute inhibition of matrix metalloproteinases has been shown to prevent cardiac rupture after an acute myocardial infarction but longterm administration was associated with impaired angiogenesis and cardiac failure. ${ }^{36}$ In our study of chronic myocardial ischemia, we showed that GSK- $3 \beta$ inhibition was associated with decreased expression of the matrix matalloproteinase-9 in the ischemic myocardial tissue.

GSK- $3 \beta$ inhibition was also associated with decreased oxidative stress in the ischemic and nonischemic myocardial tissue. GSK- $3 \beta$ is thought to be cardioprotective by reducing oxidative stress and modulating various mitochondrial pathways including modulation of the mPTP. ${ }^{26,27}$ MCL-1 inhibits mitochondrial cell stress and apoptosis. MCL-1 inhibits mitochondrial proapoptotic protein Bak, preventing it from oligomerizing and thus blocking complete formation of mPTP, which ultimately leads to the release of AIF and activation of the caspase apoptotic cascade. GSK- $3 \beta$ phosphorylates and inhibits MCL- 1 at serine 140 and inactivates it. ${ }^{6,8,23}$ Thus, inhibition of
GSK-3 $\beta$ should promote antiapoptotic activity of MCL-1. We found decreased phosphorylation of MCL-1 (Ser 140) in the GSK-3 $\beta$ inhibited group compared with the control group. This suggests a mechanism through which GSK$3 \beta$ inhibition is antiapoptotic and confirms its decreased GSK- $3 \beta$ activity. In addition, AIF released from mitochondria and cleaved caspase 3 are both downstream effector proteins and function to induce cellular apoptosis. We found decreased expression of AIF and cleaved caspase 3 (to total caspase 3 ) in the GSK-3 $\beta$ inhibited group compared with the control group.

Finally, we saw a decrease in MMP-9 and AIF in the ischemic myocardial tissue of the GSK- $3 \beta$ inhibited group compared with the control; however, we saw no change in expression levels of these 2 proteins in the nonischemic tissue between groups. This difference is likely associated with the difference in cellular conditions between the 2 areas of the myocardium.

Using this model, we have previously shown that inhibition of GSK- $3 \beta$ increases blood flow and vessel density in the ischemic and nonischemic myocardial tissue. In this study, we show inhibition of GSK-3 $\beta$ also decreases collagen formation and oxidative stress in the ischemic territory as well as nonischemic remote myocardial tissue. Our 


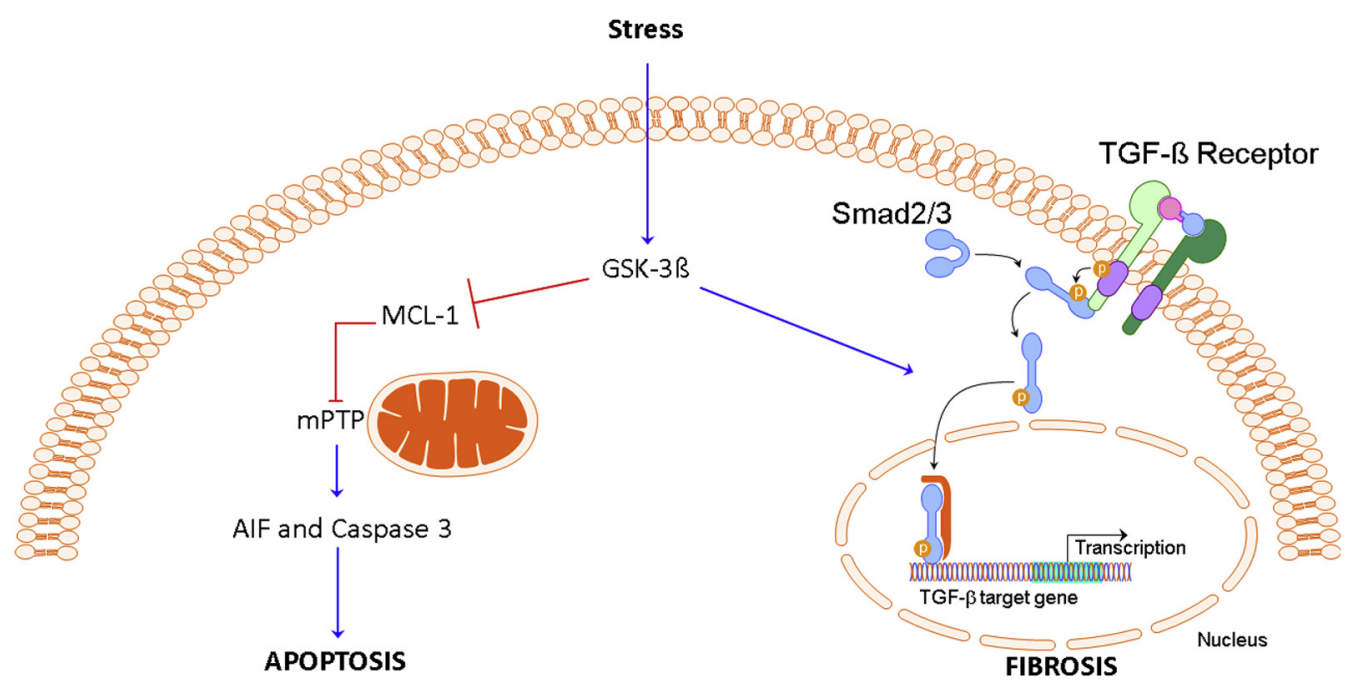

FIGURE 8. Glycogen synthase kinase $3 \beta(G S K-3 \beta)$ inhibition decreases myocardial fibrosis and oxidative stress in a pig model of chronic myocardial ischemia and metabolic syndrome. GSK-3 $\beta$ inhibition decreases mitochondrial proapoptotic and transforming growth factor- $\beta$ (TGF- $\beta$ )/SMAD2/3 signaling in the myocardium of metabolic syndrome pigs. AIF, Apoptosis inducing factor; $m P T P$, mitochondrial permeability transition pore; $M C L-1$, myeloid cell leukemia sequence-1.

research suggests that inhibition of GSK-3 $\beta$ is cardioprotective by increasing myocardial perfusion, increasing vascular density, and decreasing myocardial fibrosis and oxidative stress.

\section{Limitations}

It is unknown if the antifibrotic and antiapoptotic effects in this study are because of improved blood flow or potentially other direct targets in fibroblasts and the myocardium.

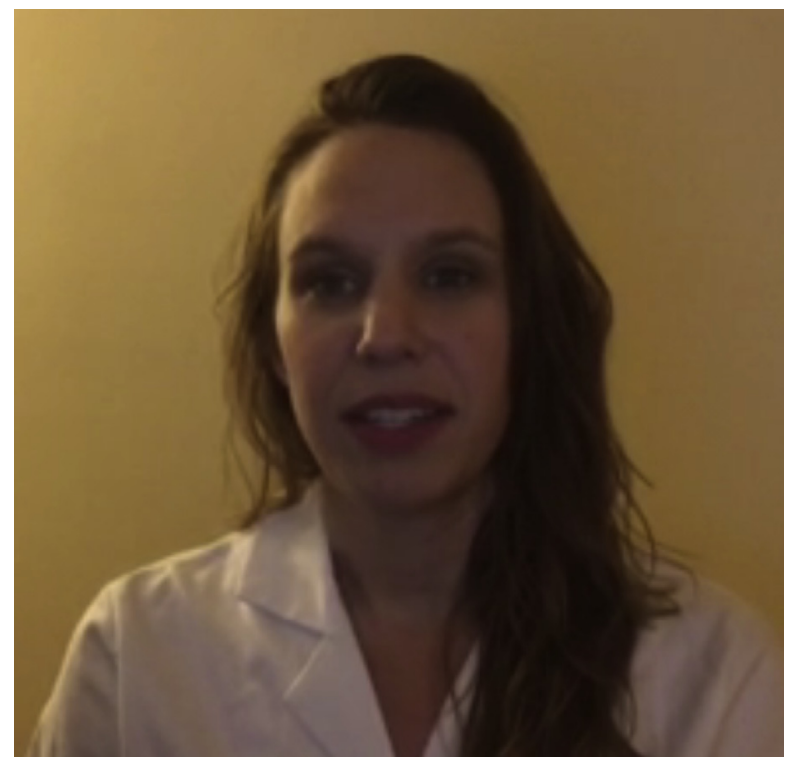

VIDEO 1. Brittany A. Potz describing the potential significance of glycogen synthase kinase $3 \beta$ inhibition as a therapy to inhibit myocardial fibrosis for patients suffering from coronary artery disease. Video available at: http://www.jtcvsonline.org/article/S0022-5223(18)30268-X/fulltext.
For instance, hypoxia is a known driver of oxidative stress and reactive oxygen species production; improved blood flow should limit reactive oxygen species and reduce apoptosis and fibrosis. Additional investigation will be required to sort out the specific targets and mechanisms of action in each of the many cell types present in the myocardium. The GSK-3 $\beta$ I was given over 5 weeks and the tissue was analyzed at the end of the study, at only 1 time point. Future research should include performing a dose response curve to identify the optimal time and duration of drug treatment.

\section{CONCLUSIONS}

We examined the role of GSK-3 $\beta$ inhibition on myocardial fibrosis and oxidative stress in the setting of chronic myocardial ischemia and metabolic syndrome. We found that inhibition of GSK- $3 \beta$ decreases collagen formation and oxidative stress in the ischemic territory as well as nonischemic remote myocardial tissue. GSK- $3 \beta$ might have this beneficial effect by downregulating TGF- $\beta /$ SMAD $2 / 3$ signaling and decreasing mitochondrial-induced cellular stress. Myocardial fibrosis and oxidative stress leads to aberrant myocardial architecture, resulting cardiac dysfunction and heart failure. ${ }^{14}$ Hyperglycemia as well as ischemic disease contribute to the development of cardiac fibrosis. ${ }^{14,15}$ Therefore, the results of this research might provide a potential mechanism for medical therapy of patients suffering from coronary artery disease and metabolic syndrome (Video 1).

\section{Conflict of Interest Statement}

Authors have nothing to disclose with regard to commercial support. 


\section{References}

1. Ford ES, Giles WH, Dietz WH. Prevalence of the metabolic syndrome among US adults. JAMA. 2005;287:14-7.

2. Galassi A, Reynolds K, He J. Metabolic syndrome and risk of cardiovascular disease: a meta-analysis. Am J Med. 2006;119:812-9.

3. Malik S. Impact of the metabolic syndrome on mortality from coronary heart disease, cardiovascular disease, and all causes in United States adults. Circulation. 2004;110:1245-50.

4. Abaci A, Oguzhan A, Kahraman S, Eryol NK, Unal S, Arinc H, Ergin A. Effect of diabetes mellitus on formation of coronary collateral vessels. Circulation. 1999; 99:2239-42.

5. Wu D, Pan W. GSK3: a multifaceted kinase in Wnt signaling. Trends Biochem Sci. 2011;35:161-8.

6. Sutherland C. What are the bona fide GSK3 substrates?. Int J Alzheimers Dis. 2011;2011:505607.

7. Hoang MV, Nagy JA, Senger DR. Cbc42-mediated inhibition of GSk-3B improves angio-architecture and lumen formation during VEGF-driven pathological angiogenesis. Microvasc Res. 2010;81:34-43.

8. Miura T, Miki T. GSK-3 $\beta$, a therapeutic target for cardiomyocyte protection. Circ J. 2009;73:1184-92.

9. Kerkela R, Kockeritz L, Macaulay K, Zhou J, Doble BW, Beahm C, et al. Deletion of GSK-3 $\beta$ in mice leads to hypertrophic cardiomyopathy secondary to cardiomyoblast hyperproliferation. J Clin Invest. 2008;118:3609-18.

10. Sambasivarao SV. Moderate GSK-3B inhibition improves neovascular architecture, reduces vascular leakage and reduces retinal hypoxia in a model of ischemic retinopathy. Angiogenesis. 2010;13:269-77.

11. Cline GW, Johnson K, Regittnig W, Perret P, Tozzo E, Xiao L, et al. Effects of a novel glycogen synthase kinase-3 inhibitor on insulin-stimulated glucose metabolism in Zucker diabetic fatty (falfa) rats. Diabetes. 2002:51:2903-10.

12. Liberman Z, Eldar-Finkelman H. Serine 332 phosphorylation of insulin receptor substrate- 1 by glycogen synthase kinase-3 attenuates insulin signaling. $J$ Biol Chem. 2005;280:4422-8.

13. Singh SP, Tao S, Fields TA, Webb S, Harris RC, Rao R. Glycogen synthase kinase-3 inhibition attenuates fibroblast activation and development of fibrosis following renal ischemia/reperfusion in mice. Dis Model Mech. 2015;8:931-40.

14. Asbun J, Villarreal FJ. The pathogenesis of myocardial fibrosis in the setting of diabetic cardiomyopathy. J Am Coll Cardiol. 2006;47:693-700.

15. Gyöngyösi M, Winkler J, Ramos I, Do Q, Firat H, McDonald K, et al. Myocardial fibrosis: biomedical research from bench to bedside. Eur J Heart Fail. 2017;19: 177-91.

16. Griffiths HR, Dias IH, Willetts RS, Devitt A, Steinbacher P, Eckl P, et al. Oxidative stress and microRNAs in vascular diseases. Free Radic Biol Med. 2015;2:17319-46

17. Fan D, Takawale A, Lee J, Kassiri Z. Cardiac fibroblasts, fibrosis and extracellular matrix remodeling in heart disease. Fibrogenesis Tissue Repair. 2012;5:15.

18. Fana GP, Wanga W, Zhaoa H, Zhanga LCP-D, Yangb Z-H, Zhanga J, Wanga X. Pharmacological inhibition of focal adhesion kinase attenuates cardiac fibrosis in mice cardiac fibroblast and post-myocardial-infarction models. Cell Physiol Biochem. 2015;37:515-26

19. Woulfe KC, Gao E, Lal H, Harris D, Fan Q, Vagnozzi R, et al. Glycogen synthase kinase-3B regulates post-myocardial infarction remodeling and stress-induced cardiomyocyte proliferation in vivo. Circ Res. 2010;106:1635-45.

20. Lal H, Ahmad F, Woodgett J, Force T. The GSK-3 family as therapeutic target for myocardial diseases. Circ Res. 2015;3:138-50.

21. Park SS, Zhao H, Mueller R, Xu Z. Bradykinin prevents reperfusion injury by targeting mitochondrial permeability transition pore through glycogen synthase kinase 3beta. J Mol Cell Cardiol. 2006:40:708-16.

22. Zhao D, Yang J, Yang L. Insights for oxidative stress and mTOR signaling in myocardial ischemia/reperfusion injury under diabetes. Oxid Med Cell Longev. 2017;2017:1-12.

23. Wagman AS, Maurer U, Dejardin E, Green DR. Glycogen synthase kinase-3 regulates mitochondrial outer membrane permeabilization and apoptosis by destabilization of MCL-1. Mol Coll. 2006;21:749-60.

24. Gross ER, Hsu AK, Gross GJ. Opioid-induced cardioprotection occurs via glycogen synthase kinase $\beta$ inhibition during reperfusion in intact rat hearts. Circ Res. 2004:94:960-6.

25. Lal H, Ahmad F, Zhou J, Zhou J, Yu JE, Ronald J, Guo Y. Cardiac fibroblast GSK-3 $\beta$ regulates ventricular remodeling and dysfunction in ischemic heart. Circulation. 2014;130:419-30.

26. Das S, Wong R, Rajapakse N, Murphy E, Steenbergen C. Glycogen synthase kinase 3 inhibition slows mitochondrial adenine nucleotide transport and regulates voltage-dependent anion channel phosphorylation. Circ Res. 2008; 103:983-91.

27. Juhaszova M, Zorov DB, Yaniv Y, Nuss HB, Wang S, Sollott SJ. Role of glycogen synthase kinase-3 $\beta$ in cardioprotection. Circ Res. 2010;104:1240-52.

28. Lassaletta AD, Chu LM, Robich MP, Elmadhun NY, Feng J, Burgess TA, et al Overfed Ossabaw swine with early stage metabolic syndrome have normal coronary collateral development in response to chronic ischemia. Basic Res Cardiol. 2012;107:243-64.

29. Potz BA, Sabe AA, Elmadhun NY, Feng J, Clements RT, Abid MR, et al Glycogen synthase kinase 3B inhibition improves myocardial angiogenesi and collateral-dependent perfusion in a swine model of metabolic syndrome. Am Heart Assoc. 2016;5:e003694.

30. Potz BA, Sabe AA, Elmadhun NY, Feng J, Liu Y, Mitchell H, et al. Calpain inhibition decreases myocardial apoptosis in a swine model of chronic myocardial ischemia. Surgery. 2015:158:445-52.

31. Zhao X, Hua Y, Chen H, Yang H, Zhang T, Huang G, et al. Aldehyde dehydrogenase- 2 protects against myocardial infarction-related cardiac fibrosis through modulation of the Wnt/ $\beta$-catenin signaling pathway. Ther Clin Risk Manag. 2015:11:1371-81.

32. Nishihara M, Miura T, Miki T, Sakamoto J, Tanno M, Kobayashi H, et al Erythropoietin affords additional cardioprotection to preconditioned hearts by enhanced phosphorylation of glycogen synthase kinase-3. Am J Physiol Heart Circ Physiol. 2006;291:748-55.

33. Tateishi A, Matsushita M, Asai T, Masuda Z, Kuriyama M, Kanki K, et al. Effect of inhibition of glycogen synthase kinase- 3 on cardiac hypertrophy during acute pressure overload. Gen Thorac Cardiovasc Surg. 2010;58:265-70.

34. Van Linthout S, Seeland U, Riad A, Eckhardt O, Hohl M, Dhayat N, et al Reduced MMP-2 activity contributes to cardiac fibrosis in experimental diabetic cardiomyopathy. Basic Res Cardiol. 2008;103:319-27.

35. Heymans S, Schroen B, Vermeersch P, Milting H, Gao F, Kassner A, et al. Increased cardiac expression of tissue inhibitor of metalloproteinase- 1 and tissue inhibitor of metalloproteinase-2 is related to cardiac fibrosis and dysfunction in the chronic pressure-overloaded human heart. Circulation. 2005;112:1136-44.

36. Heymans S, Luttun A, Nuyens D, Theilmeier G, Creemers E, Moons L, et al Inhibition of plasminogen activators or matrix metalloproteinases prevents cardiac rupture but impairs therapeutic angiogenesis and causes cardiac failure. Nat Med. 1999:5:1135-42.

Key Words: metabolic syndrome, chronic coronary ischemia, glycogen synthase kinase 3B, oxidative stress, collagen

\section{Discussion}

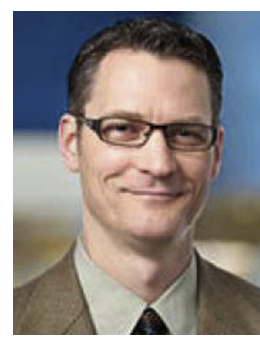

Moderator. The next paper to be presented has a long title; it's "Glycogen Synthase 3 Beta Inhibition and Its Effects on a Swine Model of Chronic Myocardial Ischemia and Metabolic Syndrome," to be presented by Brittany Potz from Brown University.

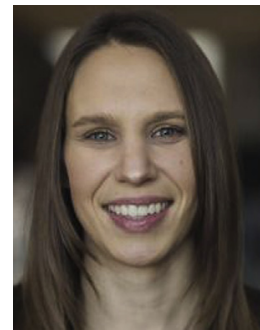

Brittany Potz (Providence, RI). Good morning, and thank you to the Western Thoracic Surgical Association for the opportunity to present our research today. It's truly an honor to be here, and thank you to both of the moderators.

Glycogen synthase kinase 3 beta is a serine threonine kinase that regulates a diverse range of cellular pathways. GSK hyperactivation is associated 
with several pathological conditions including diabetes, obesity, inflammation, ischemia, myocardial fibrosis, and mitochondrial induced oxidative stress. Inhibition of GSK 3 beta has been found to be beneficial and to reverse some of these pathologic conditions. Hyperglycemia and ischemic disease both contribute to the accumulation of myocardial collagen leading to aberrant myocardial architecture fibrosis and ultimately resulting in cardiac dysfunction and heart failure. Mitochondrial oxidative stress leads to opening of the mitochondrial permeability transition pore, which plays a critical role in myocardial apoptosis. GSK 3 beta inhibition is thought to be cardioprotective by modulating fibrosis signaling, cardiomyocyte hypertrophy, reducing oxidative stress, and preventing myocardial permeability transition pore opening in the ischemic myocardium. We utilized a chronic coronary artery disease ischemia model in the setting of metabolic syndrome. This model adequately represents the microcirculatory and metabolic dysfunction associated with metabolic syndrome observed in adult patients with coronary artery disease. Using the swine model, we have found that inhibition of GSK 3 beta increases myocardial blood flow and capillary and arteriolar density in both the ischemic and nonischemic myocardial tissue. We also found using Western blot analysis, that GSK 3 beta inhibition modulates pathways involved in sole survival in angiogenesis as indicated by the red arrows. The objective of this study was to examine the effects of inhibition of GSK 3 beta on myocardial fibrosis in oxidative stress in the setting of chronic myocardial ischemia and metabolic syndrome. We hypothesized that GSK 3 beta inhibition would have a protective effect on myocardial collagen formation and oxidative stress in the chronically ischemic myocardial tissue in a clinically relevant swine model of chronic ischemia and metabolic syndrome. To induce metabolic syndrome, Yorkshire swine were fed a high cholesterol diet for 4 weeks. We found that this induces hyperlipidemia, obesity, hypertension, and impaired insulin sensitivity. To induce chronic myocardial ischemia, the pigs then underwent placement of an ameroid constrictor on the left circumflex artery, a mini-left thoracotomy was performed, and the lung was retracted out of the way. The pericardium was opened and 0 silk sutures were used to elevate the heart into the surgical field. The left atrial appendage was retracted and the anterior descending artery and left circumflex artery were identified and the left circumflex artery isolated. Finally, an ameroid constrictor was placed on the left circumflex artery. The ameroid constrictor consists of a titanium ring with a hydrophilic core. In about 10-20 days the hydrophilic core will slowly cause to induce chronic myocardial ischemia. Two weeks later, animals received either no drug or a GSK 3 beta inhibitor. The GSK 3 beta inhibitor used is a cell-permeable peptide inhibitor that acts by binding to the substrate pocket. The high cholesterol diet and drug were continued for 5 weeks, after which the pig was euthanized and the left ventricular myocardium was harvested and analyzed. We found that inhibition of GSK 3 beta decreased fibrosis and collagen deposition in both the ischemic and nonischemic myocardial tissue, as demonstrated by Picrosirius staining. Cardiac fibrosis is associated with upregulation of the TGF beta SMAD pathway and dysregulation of the extracellular matrix. Using Western blood analysis, we found that GSK 3 beta inhibition is associated with decrease expression of the profibrotic cytokine, TGF beta, and phosphorylation of its downstream factor, SMAD2/3, in the nonischemic myocardial tissue.

In the ischemic myocardial tissue, GSK 3 beta inhibition was associated with decreased expression of TGF beta and phospho-SMAD2/3 as well. Additionally, GSK 3 beta inhibition was associated with decreased expression of matrix metalloproteinase 9 in the ischemic tissue. This suggests a mechanism through which GSK 3 beta may induce decreased fibrosis in the setting of chronic myocardial ischemia and metabolic syndrome.

OxyBlot analysis revealed that GSK 3 beta inhibition was associated with decreased oxidative stress in the ischemic and the nonischemic myocardial tissue. GSK 3 beta inhibition is thought to be cardioprotective by modulating various mitochondrial pathways including modulation of the mitochondrial permeability transition pore. Myeloid cell leukemia sequence 1 works to inhibit mitochondrial cell stress in apoptosis. MCL1 inhibits mitochondrial proapoptotic protein back, preventing it from forming a mitochondrial permeability pore, which ultimately leads to the release of apoptosis inducing factor and activation of the cast base of proapoptotic cascade. GSK 3 beta phosphorylates and inhibits myeloid cell leukemia sequence 1 at serine 140 and inactivates it, thus inhibition of GSK 3 beta should promote the antiapoptotic activity of MCL1. We found decreased expression of a phosphorylated myeloid cell left upper extremity sequence 1 at serine 140 in the GSK 3 beta inhibited group, compared with the control. This suggests a mechanism through which GSK 3 beta inhibition is antiapoptotic and confirms decreased GSK 3 beta activity. In addition, apoptosis inducing factor in glia caspase-3 are both downstream effector proteins released from mitochondria and function to induce apoptosis. We found decreased expression of apoptosis inducing factor in glia caspase-3 in the ischemic myocardial tissue in the GSK 3 beta inhibited group compared with the control. In the nonischemic myocardial tissue, we 
similarly found decreased expression of phospho-MCL1 and glia caspase- 3 .

So, we conclude that inhibition of GSK 3 beta decreases collagen formation and oxidative stress in both the ischemic territory and nonischemic remote myocardial tissue. GSK 3 beta may be having this beneficial effect by downregulating the TGF SMAD signaling pathway and decreasing mitochondria-induced cellular stress. Myocardial fibrosis and oxidative stress lead to aberrant myocardial architecture resulting in cardiac dysfunction and heart failure. Both hyperglycemia and ischemia disease contribute to the development of cardiac fibrosis. Therefore, the results of this research may provide a potential mechanism for medical therapy of patients suffering from coronary artery disease and metabolic syndrome. Thank you.

Moderator. The discussion will be opened by Ahmad Sheikh.

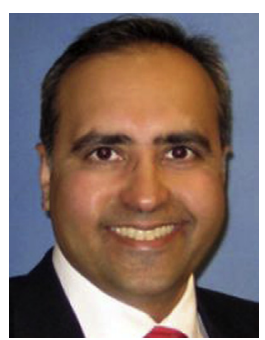

Ahmad Sheikh. Thank you Dr Potz, for such a nice presentation. I have 2 questions for you. The first has to do with the timing, the therapeutic window of timing of the GSK inhibition. In your study, you were able to induce metabolic syndrome in these swine and then subject them to an acute event that eventually turned into a chronic ischemic insult. One would imagine that the thunderclap of inflammation that occurs happens on a time scale of minutes to hours to days, and yet in the experimental design, the GSK inhibition was given 2 to 3 weeks following this initial insult. I was wondering if you could comment on why you chose that timeline and if in fact you had given the inhibitor closer to the time of the initial ischemic insult, might you have seen a more pronounced antifibrotic response and perhaps an uptick in the antiapoptotic signal?

Brittany Potz. Thank you for that question. It's a great question. In Dr Sellke's lab we do have 2 models of ischemia. We have one, an acute infarct and reperfusion model, and one a chronic ischemia model that's supposed to correlate with patients who come in who have had ischemia for a while and then you start treating them. There is some small animal studies where they do use GSK 3 beta inhibition in an acute setting and it's shown to be beneficial, so I think that's something we could certainly look at now that we've seen that the GSK 3 beta inhibition is beneficial in a chronic setting. I think you're certainly right if we start giving the GSK 3 beta inhibition the day of surgery and throughout, that we probably see perhaps even a greater effect.

Ahmad Sheikh. It might be an interesting clinical correlate because a lot of people come in with chronic ischemia, and then have the acute on chronic kind of insult.

Brittany Potz. Absolutely. Certainly.

Ahmad Sheikh. My second question has to do with physiological assessment. One of the benefits of this kind of model of course is the ability to do physiologic assessment of heart function either through in vivo noninvasive imaging such as echo, CT, MRI, or more invasive analysis with PD loops for example. I'm wondering if you and your coauthors considered doing some physiological assessment to see if there was any solitary effects of GSK inhibition on heart function?

Brittany Potz. Sure. Thank you. Again, another great question. During the harvest procedure, we do perform pressure-volume loop analysis with resting heart rate and at a heart rate of 150 beats per minute. With this inhibitor, we did not see any difference in hemodynamics. I think that might be because we gave the drug for 5 weeks, and we're looking at one time point, like we clearly saw an increase in blood flow and increase in vessel density, a decrease in collagen, so we know it's having a beneficial effect. We're wondering if maybe if we gave it a little bit longer, we might then see a change in hemodynamics.

Ahmad Sheikh. Yes. I think even if those are negative data, they might be a nice thing to include in the final version of the manuscript. It's good fodder for discussion. And thank you very much for that presentation and congratulations on some very fine work.

Brittany Potz. Thank you very much.

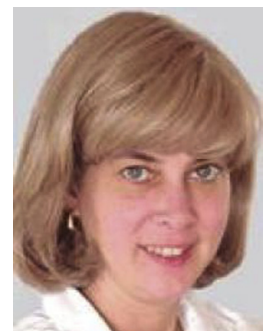

Questioner. I have one question for you. In a normal heart, nonischemic, what are the baseline levels of GSK?

Brittany Potz. That's a great question. I think it depends on really minute to minute. We didn't look at the GSK levels in the nonischemic tissue and I don't know that there's any data out there looking at human hearts, but we do know that it gets overactivated if you just compare ischemic disease with nonischemic, or even in the setting of diabetes but the exact number or activity level, I don't have but I could certainly try to get that for you.

Questioner. And finally, when we give drugs in these animal studies, the question always is, does the drug actually reach the target organ, and have the target effect on the peptide of interest? And so, did you measure serine threonine kinase levels to directly show an effect on this? Or just these downstream effectors that you presented here?

Brittany Potz. Another great question. Because we usually freeze our tissue right after the harvest, we're not able to look at activity levels, or in this situation we didn't, so we just looked at downstream markers to kind of judge activity level of the GSK 3 beta but going forward, now that we know it works, it's certainly something that we need to look at so going forward we'll try to use the nonfrozen tissue so that we could look at activity level.

Questioner. Congratulations on a nice basic science study.

Brittany Potz. Thank you very much. 